\title{
Um olhar sobre os Açores e Ponta Delgada através de seus crimes e de sua justiça
}

\author{
Deivy Ferreira Carneiro
}

SILVA, Susana Serpa. Criminalidade e Justiça na Comarca de Ponta Delgada: uma abordagem com base nos processos penais (1830-1841). Ponta Delgada: Instituto Cultural, 2003, 392 p.

Durante os séculos XVIII e XIX, assuntos ligados à pobreza, à criminalidade e a outras formas de marginalidade fomentaram urna grande diversidade de estudos no continente europeu. No caso da criminalidade, esta passou a ser vista como um grande problema social que requeria medidas drásticas para a manutenção da ordem e do bemestar da sociedade. A influência tanto do racionalismo iluminista e, posteriormente, do positivismo comtiano, juntamente com a antropologia criminal, determinaram as abordagens dos principais criminalistas do período, tanto em Portugal quanto nas suas (ex)colônias.

Contudo, é a partir do desenvolvimento da História no século XX, com a estruturação da história social, da história cultural e da história "a partir de baixo" que o estudo da criminalidade passa a ser acionado para a recuperação dos mais diversos aspectos da vida cotidiana dos grupos e indivíduos envolvidos no mundo do crime, da violência e da marginalidade.

Desde entáo, os documentos criminais têm sido utilizados, de acordo com Lê Roy Ladurie ${ }^{1}$, de duas formas distintas: como um meío ou uma fonte para o estudo dos valores e normas sociais presentes na vida dos membros das classes populares de uma determinada época histórica. Este tipo de documentação seria um dos cami- 
nhos para recuperação dos discursos de pessoas dos estratos mais pobres da sociedade e ofereceriam novas possibilidades para estudos históricos da cultura popular e da história “a partir de baixo". Em outras palavras, a leitura dos documentos criminais numa perspectiva mais qualitativa seria capaz de revelar cenas da vida cotidiana. Por outro lado, através dos mesmos documentos, seria analisada a atividade e as crenças dos profissionais do sistema jurídíco-policial, bem como, a partir primordialmente de análises quantitativas, os mecanismos de controle social e de repressão dos mais variados grupos sociais.

Procurando conciliar essas duas perspectivas, Susana Serpa Silva analisou a administração da justiça e a criminalidade entre os anos de 1830 e 1841 na comarca de Ponta Delgada, situada na ilha de São Miguel, a mais importante do arquipélago dos Açores. Ponta Delgada agrupava a maior cidade do arquipélago, sendo também uma das cidades mais importantes do Reino de Portugal. Reproduzindo quase que integralmente a Tese de Doutorado da autora defendida na Universidade de Açores em 1998, o livro é o primeiro trabalho desse porte em Açores a utilizar pro- cessos crimes em grande escala ${ }^{2}$. Esses documentos eram praticamente inexplorados e foram analisados por Silva no sentido de desvendar aspectos do cotidiano, que permitissem reconstruir um pouco da vida cole tiva, das relaçóes sociais, dos hábitos comportamentais e valores do povo de Ponta Delgada. Além disso, o trabalho procurou também perceber questóes decorrentes da segurança e da criminalidade, bem como dos mecanismos de puniçãao e de repressão e da atuação do aparato coercitivo.

O livro foi dividido em duas partes. A primeira, contendo os capítulos um e dois, disserta acerca da contextuaüzação histórica, sendo fundamental para a percepção $\mathrm{da}$ época e, conseqüentemente, da criminalidade que a caracterizou.

O primeiro capítulo faz uma contextualização do geral para o particular, ou seja, da Europa Ocidental, do continente português e dos Açores, destacando a ilha de São Miguel e o conselho de Ponta Delgada. A autora caracteriza a primeira metade do século XIX, tanto em Portugal quanto em Açores, como um período de mudanças estruturais profundas. Em Portugal, no período que vai das invasóes napoleônicas, passando pela revolução de 
1820, pelo "terror miguelista", pela reação de D. Pedro, chegando até cabralismo (1840), ocorre a ruptura definitiva com o Antigo Regime e o triunfo definitivo da causa Liberal. De acordo com Silva, Açores acompanha tudo isso de muito perto, participando da guerra civil e da transição para o liberalismo.

Com relação aos aspectos econômicos e sociais, os Açores dependiam, nesse período, de uma agricultura "atrasada e arcaica", com base na produção da laranja. Também sofriam com a falta de uma infra-estrutura básica até mesmo nas principais cidades: faltava uma rede viária significativa, reinava a miséria material e cultural entre os estratos mais pobres, o que estigmatizava boa parte da população de Ponta Delgada. Com relaçáo ao povo da ilha, este era inculto e pobre, em grande parte inofensivo, mas também marcado por comportamentos violentos e agressivos. Seus comportamentos nem sempre se coadunavam com os preceitos da moral cristá, não obstante a religiosidade que o caracterizava. $\mathrm{O}$ fosso existente entre a plebe e as elites era visível ainda nos hábitos de convívio e sociabilidade. Enquanto as famílias ricas viviam em seu próprio mundo, partilhando sua vida social em círculos familiares restritos, o povo, além dos deveres do trabalho que lhes preenchia a vida, gastava o tempo restante em lazeres festivos suscetíveis de despertarem desordens e violências, avolumadas pelo elevado índice de alcoolismo.

No segundo capítulo a autora procurou fazer uma síntese do percurso da administração judicial, destacando as formas de repressão da criminalidade, bem como os sistemas penais em curso. Segundo ela, o funcionamento da justiça em Ponta Delgada foi marcado principalmente, durante todo o período, por atropelos e incompetências. Nem mesmo com o advento do liberalismo e com as reformas judiciárias que buscavam racionalizar o campo judicial, se conseguiu resultados plenamente positivos na estruturação do poder e da administração judicial: esta permaneceu defeituosa, com multiplicidades de jurisdiçóes, magistraturas desconexas, corrupção e incompetência.

Já a segunda parte do livro, contendo os capítulos três, quatro e cinco, foi dedicada aos estudos da criminalidade e dos mecanismos de repressão e punição, sendo o terceiro capítulo a coluna vertebral do trabalho, pois além de discriminar a tipologia criminal, caracteriza os principais tipos de crimes e a sua 
ocorrência, associando-os ao contexto; ao perfil da sociedade envolvente, às relaçóes interpessoais e também aos valores e costumes dominantes.

No terceiro capítulo os crimes são divididos por ela em conjunturais e estruturais. Os conjunturais eram formados pelos crimes de lesa-majestade, fabricação de moedas falsas, emigração clandestina, contrabando e vadiagem, entre outros, intimamente ligados aos problemas políticos e econômicos acima mencionados. Com relação à mendicância e vadiagem, por exemplo, a justiça ora combatia, principalmente, com o recrutamento, ora auxiliava os mais desfavorecidos com a criação de asilos. Nesse sentido, os vadios e mendigos eram tanto um perigo quanto um lenitivo para aquela sociedade, pois, se não respeitavam suas normas, eram um mal que propiciava a prática da caridade.

Já os crimes estruturais englobavam os furtos e os roubos, as desordens, as injúrias reais e verbais, os ferimentos e os homicídios. As violências físicas, por exemplo, como na maioria dos lugares neste período, eram motivadas por rixas, inimizades, querelas particulares etc. Geralmente havia desavenças anteriores entre os envolvidos, refletindo também certa forma de se encarar a vida social. Além disso, como destacou James C. Scott ${ }^{3}$, o álcool era o motor de muitos crimes, pois enfraquecia o autocontrole, aumentando o potencial de violência. Segundo Silva, a agressividade era uma resposta recorrente aos conflitos e desencontros no seio de uma comunidade onde as forças governamentais não asseguravam a estabilidade dos vários grupos sociais.

Com respeito às injúrias verbais, estas possuíam papel relevante no jogo dos conflitos sociais, atuando como um reflexo dos padróes morais e éticos da época, sendo também uma forma de regulação das relaçóes sociais, além de atuarem como formas de socialização e integração social. $\mathrm{O}$ objetivo da injúria era quase sempre denegrir a honra, a consideração pública e o bom nome individual ou familiar do ofendido. Neste sentido, Silva relaciona os insultos com seu contexto e percebe a honra e a vergonha como valores fundamentais para aquela sociedade. Por fim, é importante ressaltar que o estudo das injúrias se torna para a autora um foco privilegiado para a análise das relaçóes sociais, dos princípios morais e dos valores mentais predominantes na sociedade. 
Tais características conferiam à criminalidade da comarca traços típicos da criminalidade inerente às comunidades rurais, próprias do Antigo Regime e das sociedades préindustrializadas. Segundo ela, não existiam rupturas abruptas entre a sociedade urbana e rural em Ponta Delgada. Na verdade, a grande diferença entre os crimes estava mais na sua quantidade do que na variedade de estilos.

Os capítulos seguintes podem ser considerados complementares ao anterior. No capítulo IV a intenção da autora é mostrar a evolução do sistema penal em Ponta Delgada no período analisado, ou seja, mostrar que modificaçóes ou tentativas de modificaçôes foram colocadas em prática no período da consolidação do liberalismo em Portugal e no arquipélago. Contudo, mesmo percebendo os esforços advindos com as legislações liberais, principalmente no que diz respeito a um maior humanismo no sistema penal e no tratamento concedido aos réus, Silva percebeu que a aplicação da justiça continuava deficiente: cheia de morosidade, marcada pela ineficiência das forças policiais, bem como marcado por um decurso processual complexo e pela desarticulação entre os vários componentes.
No quinto e último capítulo, analisando os dados referentes aos ritmos, tempos e espaços da criminalidade, a autora percebeu que $30 \%$ dos crimes ocorriam à noite; que os crimes aumentavam no verão, segundo ela, devido a maiores ajuntamentos entre as pessoas, maximizando as possibilidades de conflitos; e que a maior parte dos crimes ocorria nas freguesias urbanas, pois tais lugares ofereciam elementos (vendas, taber-nas, oficinas, ou seja, álcool, brincadeiras e brigas) que propiciavam maior incidência de conflitos. Além disso, observou-se que a maior parte dos crimes ocorreu nos espaços sociais partilhados pelos grupos sociais mais pobres.

Percebeu também que a maior parte dos crimes que chegaram à justiça tinha homens solteiros como autores (84\%) e que a violência masculina era motivada principalmente por questóes de honra pessoal, entendida na sua acepçáo de sentimentos e também de qualidades, o que motivava reaçóes às provocaçóes, rixas etc. Em suma, ser um homem em Ponta Delgada era ser um macho, manter a virilidade de modo a não manchar a sua reputação pública, garantindo assim sua própria identidade. 
Analisando os crimes envolvendo mulheres, Silva percebeu que estes estavam mais relacionados à quebra de costumes (adultério e prostituição) e era por seu intermédio que surgia a desonra masculina, o que acaba nos revelando um pouco das questóes sobre as diferenças de gênero naquela sociedade. Observou na vida familiar outro campo de conflito, no qual o homem agredia mulheres e filhos de um lado, mas de outro garantia a defesa da honra de todos. Por último a autora percebeu que a "sociedade criminal" acabava por se identificar com as classes populares. Ela chegou a essa conclusão analisando as profissóes, escolaridade, hábitos de higiene, vestuário e apelidos dos réus para chegar ao seu perfil. Assim, mais do que analisar delinqüentes, a autora viu-se imersa numa sociedade tradicional na qual a agressividade era tida como um sinal de virilidade.

Não há a menor dúvida de que o livro, em seus cinco capítulos e dezessete apêndices contendo alguns documentos-chave da análise proposta, traz importantes contribuiçôes à historiografia da criminalidade e dos Açores. O grande mérito do livro de Susana Serpa Silva é principalmente nos desvendar um dos possíveis caminhos de apreensão da sociedade de Ponta Delgada através do emaranhado de seus crimes e castigos. Contudo, gosiaiú mos de fazer algumas consideraçóes a respeito da contextualização, das fontes e do método adotado pela autora.

Com relação à documentação utilizada, apesar de ser bem diversificada, as fontes judiciais formaram a base do trabalho. Foram utilizados principalmente os processos penais, mas também autos de querela e autos policiais. Apesar de ser uma fonte excelente, não deixa de ser paradoxal, pois apesar de permitir certo acesso ao mundo daqueles que não deixaram vestígios escritos de sua história, ela os apresenta num momento de conflito e penalização, dando a impressão de que a sociedade em questão é mais conturbada do que na verdade é. Além disso, a autora tem a noçáo clara de que a criminalidade estudada não reflete a criminalidade real e sim aquela que chegou ao conhecimento do aparato jurídico. Sabe também que seu recorte é circunscrito, náo permitindo assim comparaçóes mais amplas nem conclusôes generalizantes, $\mathrm{Na}$ análise de suas fontes, Silva não toma os documentos com o sentido de evidências imediatas, vendo neles a inscrição de um real 
dado à observação e análise de historiadores. Dessa maneira, ela não fica prisioneira de formas passadas de inscrição dos fenômenos que estuda e, como tal, é capaz de repensar estas inscriçóes historicamente a partir de uma multiplicidade e não da linearidade dos fenômenos que estuda.

Com relação às questóes teórico-metodológicas, a noção de Mentalités desenvolvida por Vovelle ${ }^{4}$ é o principal guia da autora, o que, segundo ela, a ajudaria a penetrar no campo dos valores e atitudes e também a perceber os "traços psicológicos comuns aos homens da época”, ou seja, com esse aparato teórico ele pretende mesmo é perceber certas as representaçóes sociais e o "inconsciente coletivo". Acredito que Silva ganharia mais saindo do diálogo com as mentalidades e partindo para o diálogo com autores interacionistas, como, por exemplo, Fredrik Barth.

O antropólogo norueguês considera em suas análises ${ }^{5}$ as variantes comportamentais dos atores envolvidos em determinados processos sociais, ou seja, enfatiza a interação e com isso a formação de redes onde os indivíduos passam a ser o cruzamento e o ponto de interaçáo das mesmas. Barth também aponta para a importância dos contextos decisórios que colocam em interação os atores num jogo relacionai complexo (onde eles estáo posicionados munidos de recursos - limitaçóes e direitos - desiguais, o que forneceria certa dimensão de incerteza e imprevisibilidade na ação humana) definindo configurações múltiplas e variáveis segundo o caráter das decisóes a serem tomadas pelos atores históricos reais, agindo no mundo social.

Relacionado ao que foi dito acima, apesar de contextualizar muito bem seus objetos e de dividir muito bem o texto em capítulos coerentes, acredito que esse contexto poderia ser observado de uma forma mais diversa; um lugar de um jogo relacional, onde as açóes dos sujeitos históricos efetivos agindo é capaz de definir soluçóes e propor encaminhamentos que a priori náo estariam dados. Nesse sentido, a narrativa poderia ser então o relato das alternativas possíveis postas num jogo a ser decidido pelos atores históricos em questão.

Apesar das pequenas ponderações feitas acima, consideramos a obra de Susana Serpa Silva um excelente trabalho de História Social e de História da Criminalidade, sendo uma leitura obrigatória para 
estudiosos de ambos os temas, principalmente para aqueles interessados na dissoluçáo de fronteiras entre os vários campos das ciências humanas.

\section{Notas}

1 LADURIE, Emmanuel Lê Roy. "De Ia crise ultime à Ia vraie croissance 1600-1789. Violence, délinquance, contestation”. In: DUBY, George \& WALLON, Armand. Histoire de Ia France Rurale. Tomo 2: L'Age Clasúque dês Paysans de 1300 à 1789. Paris: Editions du Seuil, 1975, pp. 547.

2 Além dos processos crime, a autora utilizou principalmente documentos provenientes da administração do conselho de Ponta Delgada, imprensa, documentos presentes no Arquivo Histórico Ultramarino referentes ao Açores, legislação referente à Câmara Municipal, correspondências entre autoridades civis e jurídicas.

3 SCOTT, James C. Domination and the Arts of Resistence. Hidden Transcriptions. New Haven: Yale University Press, 1990. Passím.

4 "Histoire dês mentalités: étude des mediations et du rapport dialectique entre les conditions objectives de la vie des homes et la façon dont ils se la racontent, et meme don't ils la vivent. (...). La prospection des mentalités, loin d'être une demarche mystificatrice, à la limite deviant un élargissement essential $d u$ champ de la recherché. Non pás comme un territoire étranger, exotique, mais comme le prolangement naturel et la fine pointe de toute histoire social" VOVELLE, Michel. Idéologies \& Mentalités. Paris: Editions la Découverte, 1985, pp.17.
5 Cf.: BARTH, Fredrik. Process and form in social life, vol. 1, London: Routlegde \& Kegan Paul, 1981., BARTH, Fredrik (ed), Scale and Social Organization, Oslo: Universitesforlaget, 1978., BARTH, Fredrik. $O$ guru, o iniciador e outras variaçôes antropológicas, Rio de Janeiro, Contra-Capa, 2000., BARTH, Fredrik (ed), The Role of the Entrepreneur in Social Change in Northern Norway, Bergen, Universitetsforlaget, 1972. 